\title{
Analisis Regresi Logistik Untuk Menentukan Faktor-Faktor Yang Mempengaruhi Indeks Prestasi Kumulatif (IPK) Mahasiswa FMIPA Universitas Sam Ratulangi Manado
}

\author{
Yumira Adriani Tampil ${ }^{1}$, Hanny Komalig ${ }^{2}$, Yohanis Langi ${ }^{3 *}$ \\ 1,2,3Program Studi Matematika, Fakultas Matematika dan Ilmu Pengetahuan Alam, \\ Universitas Sam Ratulangi Manado \\ *corresponding author email : yarlangi@gmail.com
}

\begin{abstract}
Abstrak
Dalam proses pendidikan tinggi Indeks Prestasi Kumulatif (IPK) merupakan indikator keberhasilan mahasiswa. Tujuan dari penelitian ini adalah untuk mengetahui model regresi logistik biner dari IPK mahasiswa program studi Matematika dan Kimia FMIPA Unsrat Manado serta mengetahui faktor-faktor yang mempengaruhi IPK tersebut. Populasi dalam penelitian ini adalah mahasiswa aktif program studi Matematika dan Kimia T.A 2013/2014 yang berjumlah 37 mahasiswa dan T.A 2014/2015 yang berjumlah 49 mahasiswa total keseluruhan populasi adalah sebanyak 86 mahasiswa, dengan jumlah responden yang mengembalikan kuesioner penelitian sebanyak 80 responden. Indeks Prestasi Kumulatif (IPK) sebagai variabel respon (Y) dan jenis kelamin $\left(\mathrm{x}_{1}\right)$, jurusan $\left(\mathrm{x}_{2}\right)$,tempat tinggal $\left(\mathrm{x}_{3}\right)$, menerima beasiswa $\left(\mathrm{x}_{4}\right)$, daerah asal $\left(\mathrm{x}_{5}\right)$, asal sekolah $\left(\mathrm{x}_{6}\right)$, pekerjaan orang tua $\left(\mathrm{x}_{7}\right)$, biaya hidup tiap bulan $\left(\mathrm{x}_{8}\right)$ sebagai variabel prediktor dalam pencocokan model. Hasil penelitian memberikan model regresi logistik biner yaitu $\pi(\mathrm{x})=\left(\exp \left(1,502+1,397 \mathrm{x}_{2}-1,222 \mathrm{x}_{3}\right)\right) /(1+$ $\left.\exp \left(1,502+1,397 \mathrm{x}_{2}-1,222 \mathrm{x}_{3}\right)\right)$, dimana program studi dan tempat tinggal berpeluang memiliki pengaruh terhadap Indeks Prestasi Kumulatif (IPK) mahasiswa di FMIPA Unsrat Manado.
\end{abstract}

Kata Kunci: Nilai Indeks Prestasi Kumulatif (IPK), Analisis Regresi Logistik, Program Studi

\section{Logistic Regression Analysis To Determine Factors Affecting The Grade Point Average (GPA) Of FMIPA Student Of Sam Ratulangi University Of Manado}

\begin{abstract}
The study process in college stage is using Grade Point Average (GPA) as an indicator of student succes. The purpose of this research is to determine the binary logistic regression model od GPA for students majoring in mathematics and chemistry from Mathematics and Natural Science Departement in University of Sam Ratulangi Manado and to know the factors that influence the GPA itself. The population used in this research is all the active students studying mathematics and chemistry class 2013/2014 which amount 37 students and class 2014/2015 which amount 49 students, so the total population is 86 students, with the number of respondents who returned the questionnaire are 80 students. Grade Point Average (GPA) as the response variable $(Y)$ and gender $\left(x_{1}\right)$, study program $\left(x_{2}\right)$, residence $\left(x_{3}\right)$, receiving scholarship $\left(x_{4}\right)$, hometown $\left(x_{5}\right)$, previous school $\left(x_{6}\right)$, parents occupation $\left(x_{7}\right)$, monthly cost of living $\left(x_{8}\right)$ as the variable of predictor in model matching. The result of the study provide a binary logistic regression model which is $\pi(x)=\left(\exp \left(1,502+1,397 x_{2}-1,222 x_{3}\right)\right) /\left(1+\exp \left(1,502+1,397 x_{2}-1,222 x_{3}\right)\right)$, where study program $\left(x_{2}\right)$ and residence $\left(x_{3}\right)$ have the possibility to effect the Grade Point Average (GPA) achievenment of students in Mathematics and Natural Science Departement in university of Sam Ratulangi Manado.
\end{abstract}

Keywords: Grade point average (GPA), logistic regression analysis, study program.

\section{Pendahuluan}

Sebagai salah satu indikator keberhasilan mahasiswa adalah nilai yang diperolehnya tinggi yang dihitung dengan nilai rata-rata disebut Indeks Prestasi Kumulatif (IPK). Indeks Prestasi Kumulatif yang selanjutnya disingkat IPK adalah angka prestasi akademik mahasiswa yang dihitung dari semua matakuliah untuk semua semester yang sudah diikuti oleh mahasiswa [1].

Semakin baik penguasaan akademik mahasiswa maka prestasi yang diperoleh pun akan baik. Indeks Prestasi mahasiswa dipengaruhi oleh faktor dari dalam diri mahasiswa (faktor internal) 
maupun faktor dari luar diri mahasiswa (faktor eksternal). Penelitian sebelumnya tentang indeks Prestasi Kumulatif [2] dan tentang mahasiswa Universitas Sam Ratulangi Manado [3] secara khusus Fakultas MIPA [4] serta beberapa penelitian sebelumnya tentang analisis regresi logistik tapi bukan pada IPK mahasiswa $[5,6,7,8,9,10]$. Dengan demikian yang menjadi permasalahan disini adalah bagaimana mengetahui faktor-faktor yang mempengaruhi IPK mahasiswa maka dapat digunakan analisis regresi logistik biner.

Regresi logistik merupakan suatu metode analisis regresi dengan variabel respon merupakan variabel biner atau kategorik, untuk variabel responnya bersifat biner atau dikotomus yang terdiri dari dua kategori yaitu 0 dan 1 [11], sehingga analisis regresi logistik digunakan untuk menelaah faktor-faktor yang mempengaruhi Indeks Prestasi Mahasiswa (IPK).

\section{Analisis Regresi}

Analisis regresi merupakan salah satu analisis yang bertujuan untuk mengetahui pengaruh suatu variabel terhadap variabel lain. Model regresi yang paling sederhana adalah model regresi linier sederhana dengan bentuk persamaan [12] :

dimana :

$$
Y=\beta_{0}+\beta_{1} X+\varepsilon
$$

$\mathrm{Y}=$ variabel terikat (nilai yang diprediksi)

$\mathrm{X}=$ variabel bebas

$\beta_{0}=$ konstanta

$\beta_{1}=$ koefisien regresi (nilai peningkatan ataupun penurunan)

$\varepsilon=$ galat acak.

\subsection{Analisis Regresi Logistik biner}

Regresi Logistik adalah suatu metode analisis statistika untuk mendeskripsikan hubungan antara variabel terikat yang memiliki dua kategori atau lebih dengan satu atau lebih peubah bebas berskala kategori atau kontinu [13]. Adapun regresi logistik dapat dibagi menjadi regresi logistik biner, regresi logistik multinomial dan regresi logistik ordinal.

Model regresi logistik biner digunakan untuk menganalisis hubungan antara satu variabel respon dan beberapa variabel prediktor, dengan variabel responnya berupa data kualitatif dikotomi yaitu bernilai 1 untuk menyatakan keberadaan sebuah karakteristik dan bernilai 0 untuk menyatakan ketidakberadaan sebuah karakteristik [10].

Model regresi logistik biner digunakan jika variabel responnya menghasilkan dua kategori bernilai 0 dan 1, sehingga mengikuti distribusi Bernoulli sebagai berikut [14] :

dimana :

$$
f\left(y_{i}\right)=\pi_{i}^{y_{i}}\left(1-\pi_{i}\right)^{1-y_{i}}
$$

$\pi_{i}=$ peluang kejadian ke-i

$y_{i}=$ peubah acak ke-i yang terdiri dari 0 dan 1

Bentuk model regresi logistik dengan satu variabel prediktor adalah [14] :

$$
\pi(x)=\frac{\exp \left(\beta_{0}+\beta_{1} x\right)}{1+\exp \left(\beta_{0}+\beta_{1} x\right)}
$$

Untuk mempermudah menaksir parameter regresi, maka $\pi(x)$ pada persamaan diatas ditransformasikan sehingga menghasilkan bentuk logit regresi logistik, sebagai berikut :

$$
g(x)=\operatorname{In}\left[\frac{\pi(x)}{1-\pi(x)}\right]=\beta_{0}+\beta_{1} x
$$

\subsection{Pendugaan Parameter}

Penyelesaian untuk mengestimasi parameter yang belum diketahui dapat menggunakan metode Maximum Likelihood Estimation (MLE). Pada dasarnya metode maximum likelihood 
memberikan nilai estimasi $\beta$ untuk memaksimumkan fungsi likelihood [10]. Secara sistematis, fungsi likelihood untuk model regresi logistik biner adalah sebagai berikut [13] :

dimana :

$$
l(\beta)=\prod_{i=1}^{n} \pi\left(x_{i}\right)^{y_{i}}\left[1-\pi\left(x_{i}\right)\right]^{1-y_{i}}
$$

$y_{i} \quad=$ pengamatan pada variabel ke-i

$\pi\left(x_{i}\right)=$ peluang untuk variabel prediktor ke-i

Untuk memudahkan perhitungan maka dilakukan pendekatan log likelihood, didefinisikan sebagai [13]:

$$
L(\beta)=\sum_{i=1}^{n}\left\{y_{i} \ln \left[\pi\left(x_{i}\right)\right]+\left(1-y_{i}\right) \ln \left[1-\pi\left(x_{i}\right)\right]\right\}
$$

Untuk mendapatkan nilai penafsiran koefisien regresi logistik $(\hat{\beta})$ dilakukan dengan membuat turunan pertama $L(\beta)$ terhadap $\beta$ dan disamakan dengan 0 .

\subsection{Uji Model Regresi Logistik}

Uji model dilakukan untuk memeriksa peranan variabel prediktor terhadap variabel respon secara serentak atau secara keseluruhan. Uji serentak ini disebut juga uji model chi square [10]. Hipotesis untuk uji ini adalah sebagai berikut :

$H_{0}: \beta_{1}=\beta_{2}=\cdots=\beta_{i}=0$

$H_{1}$ : paling sedikit ada satu parameter $\beta_{i} \neq 0$

Statistik uji G atau Likelihood Ratio Test :

dimana :

$$
G=-2 \ln \left[\frac{\left(\frac{n_{1}}{n}\right)^{n_{1}}\left(\frac{n_{0}}{n}\right)^{n_{0}}}{\prod_{i=1}^{n} \widehat{\pi}_{i}^{y_{i}}\left(1-\widehat{\pi}_{i}\right)^{1-y_{i}}}\right]
$$

$n_{1}=$ banyaknya observasi yang berkategori 1

$n_{0}=$ banyaknya observasi yang berkategori

Statistik uji $G$ mengikuti distribusi chi-square, sehingga untuk memperoleh keputusan dilakukan perbandingan dengan nilai $\chi^{2}$ tabel, dengan derajat bebas $(\mathrm{db})=\mathrm{k}-1, \mathrm{k}$ merupakan banyaknya variabel prediktor. Kriteria penolakan (tolak $H_{0}$ ) jika nilai $G>\chi_{(d b, \alpha)}^{2}$ atau jika P-value $<\alpha$.

\subsection{Uji Hipotesis Parsial}

Pengujian parsial digunakan untuk menguji pengaruh setiap $\beta_{i}$ secara individual dalam model yang diperoleh. Hasil pengujian secara parsial/individual akan menunjukkan apakah suatu variabel prediktor layak untuk masuk dalam model atau tidak [14]. Hipotesis yang digunakan untuk setiap variabel adalah sebagai berikut :

$$
\begin{aligned}
& H_{0}: \beta_{i}=0 \\
& H_{1}: \beta_{i} \neq 0
\end{aligned}
$$

Statistik uji Wald (W) :

dan

$$
W=\frac{\widehat{\beta}_{i}}{S E\left(\widehat{\beta}_{i}\right)}
$$

$$
S E\left(\hat{\beta}_{i}\right)=\sqrt{\left(\sigma^{2}\left(\hat{\beta}_{i}\right)\right)}
$$

dimana :

$$
\begin{array}{ll}
S E\left(\hat{\beta}_{i}\right) & =\text { dugaan galat baku untuk koefisien } \beta_{i} \\
\hat{\beta}_{i} & =\text { nilai dugaan untuk parameter }\left(\beta_{i}\right)
\end{array}
$$


Rasio yang dihasilkan dari statistik uji dibawah hipotesis $H_{0}$ akan mengikuti sebaran normal baku, sehingga untuk memperoleh keputusan dilakukan perbandingan dengan distribusi normal baku (Z). Kriteria penolakan (tolak $H_{0}$ ) jika nilai $W>Z_{\alpha / 2}$ atau $p-$ value $<\alpha$.

\subsection{Interpretasi Koefisien Parameter dari Variabel Dikotomi}

Secara umum, rasio peluang (odds ratio) merupakan sekumpulan peluang yang dibagi oleh peluang lainnya [4]. Nilai odds ratio didefinisikan sebagai berikut [13] :

$$
\psi=\frac{\pi(1) /[1-\pi(1)]}{\pi(0) /[1-\pi(0)]}=\frac{e^{\beta_{0}+\beta_{1}}}{e^{\beta_{0}}}=e^{\beta_{1}}
$$

Bila nilai $\psi=1$, maka antara kedua variabel tersebut tidak terdapat hubungan. Bila nilai $\psi<1$, maka antara kedua variabel terdapat hubungan negatif terhadap perubahan kategori dari nilai $\mathrm{x}$ dan demikian sebaliknya bila $\psi>1$.

\section{Metode Penelitian}

Penelitian ini dilaksanakan pada bulan Maret hingga April 2017. Penelitian ini bertempat di program studi Matematika dan Kimia, FMIPA Unsrat Manado. Pengolahan data dilakukan di Laboratorium Statistika Program Studi Matematika FMIPA Unsrat. Penelitian ini menggunakan data primer dengan menjalankan kusioner kepada mahasiswa aktif angkatan 2013 dan 2014 dalam program studi Matematika dan Kimia.

Populasi dalam penelitian ini adalah seluruh mahasiswa aktif program studi Matematika dan Kimia Tahun Akademik 2013/2014 dan 2014/2015 di FMIPA Unsrat, berjumlah 86 mahasiswa yang terdiri dari 37 mahasiswa Tahun Akademik 2013/2014 dan 49 mahasiswa Tahun Akademik 2014/2015. Dari populasi tersebut dalam pengumpulan data, terdapat missing data sebanyak 6 orang dimana dari 86 responden menjadi 80 responden yang terdiri dari 36 mahasiswa Tahun Akademik 2013/2014 dan 44 mahasiswa Tahun Akademik 2014/2015.

Variabel yang digunakan pada penelitian ini terdiri atas variabel tak bebas (variabel respon) yaitu Indeks Prestasi Kumulatif (IPK) (Y) yang dinotasikan dengan 0 untuk y $\leq$ mean dari IPK dan 1 untuk y > mean IPK serta variabel bebas (prediktor) yaitu Jenis kelamin $\left(X_{1}\right)$ dinotasikan dengan 0 untuk perempuan dan 1 untuk laki-laki, Jurusan $\left(X_{2}\right)$ dinotasikan dengan 0 untuk Kimia dan 1 untuk matematika, Tempat tinggal $\left(X_{3}\right)$ dinotasikan dengan 0 untuk bukan kost dan 1 untuk kost, Menerima Beasiswa $\left(X_{4}\right)$ dinotasikan dengan 0 untuk tidak dan1 untuk ya, Daerah asal $\left(X_{5}\right)$ dinotasikan dengan 0 untuk luar Sulawesi Utara dan 1 untuk Sulawesi Utara, Asal sekolah $\left(X_{6}\right)$ dinotasikan dengan 0 untuk SMK dan 1 untuk SMA, Pekerjaan orang tua $\left(X_{7}\right)$ dinotasikan dengan 0 untuk bukan pegawai negeri dan 1 untuk pegawai negeri, Biaya hidup tiap bulan $\left(X_{8}\right)$ dinotasikan dengan 1 untuk $\leq 1.000 .000$ dan dinotasikan dengan 0 untun $>1.000 .000$.

Langkah-langkah analisis data adalah sebagai berikut:

1. Pengumpulan data lewat kuesioner

2. Mencari nilai rata-rata IPK dari 80 responden dengan menggunakan rumus $\bar{x}=\frac{\sum_{i=1}^{n} x_{i}}{n}$ sehingga diperoleh $\bar{x}=3,310$.

3. Menentukan model regresi logistik

4. Melakukan uji hipotesis berganda atau uji model dengan menggunakan statistik uji G

5. Melakukan uji hipotesis parsial dengan menggunakan statistik uji Wald

6. Melakukan analisis pengaruh setiap variabel biner dengan menggunakan odds ratio

7. Menarik kesimpulan berdasarkan hasil analisis yang diperoleh. 


\section{Hasil dan Pembahasan}

\subsection{Model Regresi Logistik}

Dengan menggunakan bantuan softwere maka diperoleh model regresi logistik dari Indeks Prestasi Kumulatif (IPK) mahasiswa di FMIPA UNSRAT sebagai berikut :

$$
\pi(x)=\frac{\exp \left(\begin{array}{c}
1,268-0,027 X_{1}+1,294 X_{2}-1,151 X_{3} \\
+0,318 X_{4}-0,738 X_{5}-1,001 X_{6}+0,805 X_{7}+0,00 X_{8}
\end{array}\right)}{1+\exp \left(\begin{array}{c}
1,268-0,027 X_{1}+1,294 X_{2}-1,151 X_{3} \\
+0,318 X_{4}-0,738 X_{5}-1,001 X_{6}+0,805 X_{7}+0,00 X_{8}
\end{array}\right)}
$$

Uji serentak dilakukan untuk melihat pengaruh variabel prediktor secara keseluruhan terhadap variable respon denga menggunakan bantuan softwere maka diperoleh hasil seperti pada table 1.

Tabel 1. Hasil Uji Serentak

\begin{tabular}{|cl|r|}
\hline Iteration & & $\begin{array}{c}-2 \text { Log } \\
\text { likelihood }\end{array}$ \\
\hline Step 0 & 1 & 108,441 \\
& 2 & 108,441 \\
3 & 108,441 \\
\hline
\end{tabular}

Berdasarkan hasil uji serentak yang dapat dilihat dari nilai -2 log likelihood pada tabel 1 maka diperoleh nilai $G=108,441$. Dengan menggunakan $\alpha=5 \%$ maka diperoleh $\chi_{(d b, \alpha)}^{2}=100,75$, karena $G>\chi^{2}{ }_{(d b, \alpha)}$ maka tolak $H_{0}$ yang artinya terdapat paling sedikit ada satu parameter $\beta_{i} \neq 0$ di mana terdapat satu atau lebih variabel prediktor yang berpengaruh signifikan terhadap variabel respon.

\subsection{Uji Parsial Variabel Model}

Uji parsial dilakukan untuk melihat pengaruh setiap variabel prediktor terhadap variabel respon dengan menggunakan bantuan software maka diperoleh hasil seperti pada tabel 2.

Tabel 2. Hasil Uji Parsial

\begin{tabular}{|c|c|c|c|c|c|c|c|}
\hline & B & S.E. & Wald & $d f$ & Sig. & $\operatorname{Exp}(\mathrm{B})$ \\
\hline \multirow[t]{9}{*}{ Step 1a } & $\mathrm{X} 1$ & .005 & .531 & .000 & 1 & .992 & 1.005 \\
\hline & $X 2$ & 1.397 & .592 & 5.570 & 1 & .018 & 4.043 \\
\hline & X3 & -1.222 & .611 & 3.995 & 1 & .046 & .295 \\
\hline & X4 & .365 & .546 & .447 & 1 & .504 & 1.441 \\
\hline & $\times 5$ & -.775 & .582 & 1.771 & 1 & 183 & .461 \\
\hline & $X_{6}$ & -.986 & 1.249 & .623 & 1 & .430 & .373 \\
\hline & X7 & .736 & .647 & 1.296 & 1 & .255 & 2.088 \\
\hline & X8 & .574 & .588 & .952 & 1 & .329 & 1.775 \\
\hline & Constant & 1.502 & 1.598 & .884 & 1 & .347 & 4.492 \\
\hline
\end{tabular}

Dengan memperhatikan hasil uji parsial maka dapat diperoleh model regresi logistik biner untuk IPK mahasiswa FMIPA Unsrat yaitu sebagai berikut :

$$
\pi(x)=\frac{\exp \left(1,502+1,397 X_{2}-1,222 X_{3}\right)}{1+\exp \left(1,5021,397 X_{2}-1,222 X_{3}\right)}
$$

\subsection{Interpretasi Nilai Odds Ratio}

Berdasarkan nilai odds ratio yang dapat dilihat dari nilai $\exp (\beta)$ dari hasil output dari uji parsial, besarnya perbedaan kecenderungan dari setiap variabel prediktor adalah sebagai berikut : 
a. Jenis kelamin $\left(X_{1}\right)$

Peluang seorang mahasiswa dengan jenis kelamin laki-laki memiliki kecenderungan indeks prestasi kumulatif (IPK>3,310) adalah sebesar 1,005 kali dari pada mahasiswa dengan jenis kelamin perempuan.

b. Jurusan $\left(X_{2}\right)$

Peluang seorang mahasiswa jurusan Matematika memiliki kecenderungan indeks prestasi kumulatif (IPK > 3,310)adalah sebesar 4,043 kali dari pada mahasiswa jurusan Kimia.

c. Tempat tinggal $\left(X_{3}\right)$

Peluang seorang mahasiswa yang tinggal di kost memiliki kecenderungan indeks prestasi kumulatif (IPK > 3,310) adalah sebesar 0,295 kali dari mahasiswa yang tingga dengan orang tua.

d. Menerima beasiswa $\left(X_{4}\right)$

Peluang seorang mahasiswa yang menerima beasiswa memiliki kecenderungan indeks prestasi kumulatif (IPK>3,310) adalah sebesar 1,441 kali dari pada mahasiswa yang tidak menerima beasiswa.

e. Daerah asal $\left(X_{5}\right)$

Peluang seorang mahasiswa yang berasal dari Sulawesi Utara memiliki kecenderungan indeks prestasi kumulatif (IPK>3,310) adalah sebesar 0,461 kali dari mahasiswa yang berasal dari luar Sulawesi Utara.

f. Asal sekolah $\left(X_{6}\right)$

Peluang seorang mahasiswa yang berasal sekolah SMA memiliki kecenderungan indeks prestasi kumulatif (IPK> 3,310) adalah sebesar 0,373 kali dari mahasiswa yang berasal sekolah SMK.

g. Pekerjaan orangtua $\left(X_{7}\right)$

Peluang seorang mahasiswa pekerjaan orang tuanya sebagai pegawai negeri memiliki kecenderungan indeks prestasi (IPK >3,310) adalah sebesar 2,088 kali dari pada mahasiswa yang pekerjaan orang tuanya bukan sebagai pegawai negeri.

h. Biaya hidup tiap bulan $\left(X_{8}\right)$

Peluang seorang mahasiswa dengan biaya hidup tiap bulan lebih besar atau sama dengan Rp. 1.000.000,- memiliki kecenderungan indeks prestasi kumulatif (IPK>3,310) adalah sebesar 1,775 kali dari pada mahasiswa dengan biaya hidup tiap bulan kurang dari Rp. 1.000.000,-

\section{Kesimpulan}

1. Model regresi logistik biner dari IPK mahasiswa Matematika dan Kimia FMIPA Unsrat Manado, adalah sebagai berikut :

$$
\pi(x)=\frac{\exp \left(1,502+1,397 X_{2}-1,222 X_{3}\right)}{1+\exp \left(1,502+1,397 X_{2}-1,222 X_{3}\right)}
$$

2. Berdasarkan analisis uji parsial variabel Program studi dan tempat tinggal berpeluang memiliki pengaruh terhadap Indeks Prestasi Kumulatif (IPK) mahasiswa di FMIPA Unsrat Manado

\section{Daftar Pustaka}

[1] Peraturan Rektor UNSRAT No. 01/UN12/PP/2013 tentang Pedoman Penyelenggaraan Akademik di Universitas Sam Ratulangi.

[2] Diminarni P. 2010. Pengaruh Motivasi Belajar, Gaya Belajar dan Berpikir Kritis Terhadap Indeks Prestasi Kumulatif [skripsi]. Fakultas Ekonomi Universitas Pembangunan Nasional Veteran, Jawa Timur.

[3] Lombone I., M. S. Paendong, dan Y. A. R. Langi. 2012. Tingkat Kepuasan Mahasiswa Terhadap Kualitas Pelayanan Universitas Sam Ratulangi Menggunakan Analisis Faktor. Manado. Jurnal MIPA UNSRAT Online 1(1): 52-56. 
[4] Zainal M, M., A. J. Rindengan, dan W. Ch. D. Weku. 2014. Penggunaan Association Rule Data Mining Untuk Menentukan Pola Lama Studi Mahasiswa F-MIPA UNSRAT. Jurnal de Cartesian 3(1): 1-8.

[5] Raharjanti, R. P. dan T. Widiharih. 2005. Model Logit Kumulatif Untuk Respon Ordinal. Semarang. Jurnal Matematika 8(3): 102-107.

[6] Yudissanta, A. dan M. Ratna. 2012. Analisis Pemakaian Kemoterapi Pada Kasus Kanker Payudara dengan Menggunakan Metode Regresi Logistik Multinomial ( Studi Kasus: Pasien di Rumah Sakit “X” Surabaya). Surabaya. Jurnal Sains dan Seni ITS 1(1): 112-117.

[7] Rahmadeni dan E. Safitri. 2016. Pemodelan Pasien Kanker Payudara Menggunakan Regresi Logistik Biner ( Studi Kasus : Pasien Kanker Payudara di Rumah Sakit Umum Daerah Arifin Ahmad Pekanbaru). Pekanbaru. Jurnal Sains, Teknologi dan Industri 13(2): 168-173.

[8] Imaslihkah, S., M. Ratna dan V. Ratnasari. 2013. Analisis Regresi Logistik Ordinal Terhadap Faktor-Faktor yang Mempengaruhi Predikat Kelulusan Mahasiswa S1 di ITS Surabaya. Surabaya. Jurnal Sains dan Seni POMITS 2(2): 177-182.

[9] Paputungan, N. W., Y. A. R. Langi, J. D. Prang. 2016. Analisis Regresi Logistik Ordinal Pada Tingkat Kepuasaan Pengguna Jasa Terhadap Pelayanan di Bandara Internasional Sam Ratulangi Manado. Universitas Sam Ratulangi. Manado. Jurnal de Cartesian 5(2) :72-79.

[10] Sepang, F., H. Komalig, D. Hatidja. 2012. Penerapan Regresi Logistik untuk Menentukan Faktor-Faktor yang Mempengaruhi Pemilihan Jenis Alat Kontrasepsi di Kecamatan Modayag Barat. Universitas Sam Ratulangi. Manado. Jurnal MIPA Unsrat Online 1(1):1-5.

[11] Hosmer, D.W., S. Lemeshow dan R. X. Sturdivant. 2013. Applied Logistic Regression. Edisi ke-3. John Wiley and Sons Inc, Canada.

[12] Suyono. 2015. Analisis Regresi untuk Penelitian. Deepublish, Yogyakarta.

[13] Hosmer, D.W., dan S. Lemeshow. 2000. Applied Logistic Regression.Edisi ke-2.John Wiley and Sons Inc, Canada.

[14] Agresti, A. 1990. Categorical Data Analysis.John Wiley and Sons, Inc. New York. 